1 This manuscript has been submitted for publication to

2 Geomatics, Natural Hazards and Risk. Please note that

3 the manuscript is under review and subsequent versions

4 of this manuscript may have different content. If accepted,

5 the final version of the manuscript will be available via the

6 'Peer-reviewed Publication DOI' link on this webpage.

7 Please feel free to contact the corresponding author.

8

\section{Detection and forecasting of shallow landslides: lessons from a natural laboratory}

Rupert Bainbridge ${ }^{1}$, Michael Lim², Stuart Dunning ${ }^{1}$, Mike G. Winter ${ }^{3}$, Alejandro DiazMoreno $^{1,4}$, James Martin², Hamdi Torun², Bradley Sparkes ${ }^{5}$, Muhammad Khan², Nanlin Jin ${ }^{2}$

${ }^{1}$ Department of Geography, Newcastle University, Newcastle, NE1 7RU, UK.

${ }^{2}$ Faculty of Engineering and Environment, Northumbria University, Newcastle, NE1 8ST, UK.

${ }^{3}$ Winter Associates, Kirknewton, Midlothian, EH27 8AF, UK.

${ }^{4}$ Reynolds International Ltd, Broncoed Business Park, Wrexham Rd, Mold, CH7 1HP

${ }^{5}$ Bridgeway Consulting, Bridgeway House, Riverside Way, Nottingham NG2 1DP, UK.

Corresponding author: Rupert Bainbridge (rupert.bainbridge@ newcastle.ac.uk) 
Rupert Bainbridge ${ }^{1}$, Michael Lim², Stuart Dunning, ${ }^{1}$, Mike G. Winter ${ }^{3}$, Alejandro DiazMoreno ${ }^{1,4}$, James Martin², Hamdi Torun², Bradley Sparkes ${ }^{5}$, Muhammad Khan², Nanlin Jin ${ }^{2}$

$28{ }^{1}$ Department of Geography, Newcastle University, Newcastle, NE1 7RU, UK.

$29{ }^{2}$ Faculty of Engineering and Environment, Northumbria University, Newcastle, NE1 8ST, $30 \mathrm{UK}$.

$31 \quad{ }^{3}$ Winter Associates, Kirknewton, Midlothian, EH27 8AF, UK.

$32{ }^{4}$ Reynolds International Ltd, Broncoed Business Park, Wrexham Rd, Mold, CH7 1HP

$33{ }^{5}$ Bridgeway Consulting, Bridgeway House, Riverside Way, Nottingham NG2 1DP, UK. 34

37 Key words: Debris flow, detection, forecasting, thresholds, monitoring 


\section{Abstract}

Shallow landslides are a significant hillslope erosion mechanism and limited understanding of their initiation and development results in persistent risk to infrastructure. Here, we analyse steep slopes above a strategic road, the A83 Rest and be Thankful in the west of Scotland. An inventory of 70 landslides (2003-2020) shows the development of debris flows, creep deformation and debris falls. Debris flows dominate and account for 5,350 $\mathrm{m}^{3}$ (98\%) of landslide source volume. We use novel time-lapse vector tracking to detect and quantify slope instabilities, whilst seismometers demonstrate the potential for live detection and location of debris flows. Using on-slope rainfall data, we show that landslides are typically triggered by abrupt changes in the rainfall trend, characterised by high-intensity, long duration rainstorms, sometimes part of larger seasonal rainfall changes. We derive empirical antecedent precipitation $(>62 \mathrm{~mm})$ and intensity-duration (>10 hours) thresholds over which debris flows occur. Our analysis shows the new thresholds are more effective at raising hazard alerts than the current management plan.

The low-cost combination of sensors provides vital information to notify of increasing hazard, the initiation of movement, and then final failure. This approach offers considerable advances to support operational decision-making for infrastructure threatened by complex slope hazards.

\section{Plain Language Summary}

Landslides present risks to roads, road users and economic activity. Different hillslope materials and topography determine landslide susceptibility, while weather conditions can alter the materials and the likelihood of landslides occurring, as well as directly triggering failure. These interrelated factors can limit or complicate our understanding of landslides, and makes generalisations difficult, or at least imprecise. Here we present results from low-cost local 
monitoring that produces multiple site-specific datasets to improve the management of highrisk sites. We also present a new high resolution landslide inventory for a hillside above the A83 road in the west of Scotland. Using rainfall data, in combination with recorded landslide occurrences, we determine what rainfall conditions, both leading up to and at the point at which movement starts, generate landslides at this location. A time-lapse camera allows landslides to be timed accurately and, using computer software, we calculate changes on the slope between images to detect and monitor the early stages of movement, providing vital early warning. Finally, we use seismometers to detect when movement has occurred and to pinpoint its location on the slope. These tools can be readily deployed to monitor landslide hazards at other highrisk sites on road and rail networks, and we advocate a network of local thresholds and monitoring over regional approaches to landslide risk.

\section{Introduction}

Debris flows are extremely rapid $(>5 \mathrm{~m} / \mathrm{s})$, saturated debris-rich landslides that exist along the broad spectrum of flow-like landslides (Hungr et al., 2014). Often, shallow landslides transform into debris flows given favourable material and fluidisation conditions (e.g. Zimmerman et al., 2020). Debris flow runout potential and their capacity to entrain large quantities of water and sediment make them a significant global hazard, particularly where linear infrastructure traverses affected slopes (Geertsema et al., 2009; Meyer et al., 2015). They can be broadly grouped into channelized debris flows (CDFs) that are constrained for their flow path and hillslope (or open slope) debris flows (HDFs) that occur on non-incised slopes (Chen et al., 2009). CDFs and HDFs can transition into one another where HDFs meet gullies or CDFs breach channels and flow over slopes; it is this hillslope-gully coupling that can control the hazard potential (Milne et al., 2009). CDFs often occur in torrent systems, such as the Illgraben, Switzerland (Badoux et al., 2009), where the repeated flow path removes some of the spatial risk uncertainty and allows focussed monitoring of a single outflow channel. 
However, at some sites historic evidence shows debris flows may occur from anywhere across wide areas with suitable topography and materials. This leads to both spatial and temporal uncertainty on triggering location and runout. At such sites, where the risk is high, a combination of active mitigation (physically controlling site aspects using barrier, net, pit, or deflection engineering infrastructure) and passive mitigation (reducing impacts via land-use planning, closures, and warning systems) methods can be used (Huebl and Fiebiger, 2005; Vagnon, 2020) but can be costly given the wide area of potential source and runout zones. In Scotland, debris flows have repeatedly damaged roads and rail lines resulting in economic and social costs (Winter et al. 2019a), with many valleys showing historic (and prehistoric) evidence of multiple debris flow deposits slope wide (Innes, 1983; Luckman, 1992; Curry, 2000). Contemporary infrastructure damaging debris flows have often been linked to high-intensity rainfall (Winter et al., 2019b). Climate forecasts suggest that in the future Scotland may receive more high intensity rainfall events in the winter and lower-frequency but higher-intensity rainfall during summer months (Finlayson, 2020; UKCP, 2018, Jones et al., 2013). Such changes in antecedent conditions and rainfall patterns may perturb hillslope sediment cascades (Bennett et al., 2014), releasing sediment from storage that is considered dormant, increasing the debris flow hazard in mountainous areas (Winter and Shearer, 2017).

Monitoring strategies for determining the level of landslide hazard posed by rainfall, in a given area or slope, vary from global to hyper-local in scale. Global determination of landslide hazard requires the combination of variables such as slope, lithology, soil wetness, antecedent rainfall, and rainfall (Stanley et al. 2021). Whilst useful for global and regional indications of landslide hazard, these global models do not allow detailed analysis of areas smaller than the resolution of the data. Input data are at coarse resolution which do not always accurately represent the real-world spatial variability (Ozturk et al. 2021), making predictions noisy or imprecise. Where a higher confidence in the level of landslide hazard is required for decision 
making at linear infrastructure for example, hyper-local monitoring can be deployed. Hyper-

113 local monitoring collects the detail required to make site specific thresholds for landslide

114 initiation and makes significant improvements over global landslide susceptibility models

115 (Ozturk et al. 2021).

Here we demonstrate a novel combination of near-real-time, multi-disciplinary,

117 monitoring techniques that allow remote detection and quantification of slope changes and supplement the regional Landslide Management Plan (LMP). The objective of these techniques is to improve our understanding of shallow landslide trigger mechanisms that threaten road users and infrastructure, and thus enhance alert capabilities for road asset managers at debris flow prone sites. These new, relatively low-cost, monitoring techniques and analyses are essential in helping to better manage the present and future increased risk of debris flows.

\section{Study area}

The A83 Rest and be Thankful (RabT), a key road into and out of west Scotland (Fig. 1a), bisects the south-western slope of Beinn Luibhean upslope from Glen Croe and has the highest landslide frequency on the Scottish road network (McMillan and Holt, 2019). The average slope of the RabT is $\sim 32^{\circ}$ with a relief of $\sim 580 \mathrm{~m}$. The bedrock is Schist, with overlying glacial till up to $3 \mathrm{~m}$ thick, interspersed with gullies, landslide source scars, levees and lower slope debris cones (Sparkes et al., 2017, Finlayson, 2020, BGS, 2020). The surficial till deposits extend beyond the RabT site and cover much of the lower and mid-slopes of the surrounding hills in the Trossachs mountain range (BGS, 2020) where the A83 and other strategic roads route to the west and north of Scotland. 

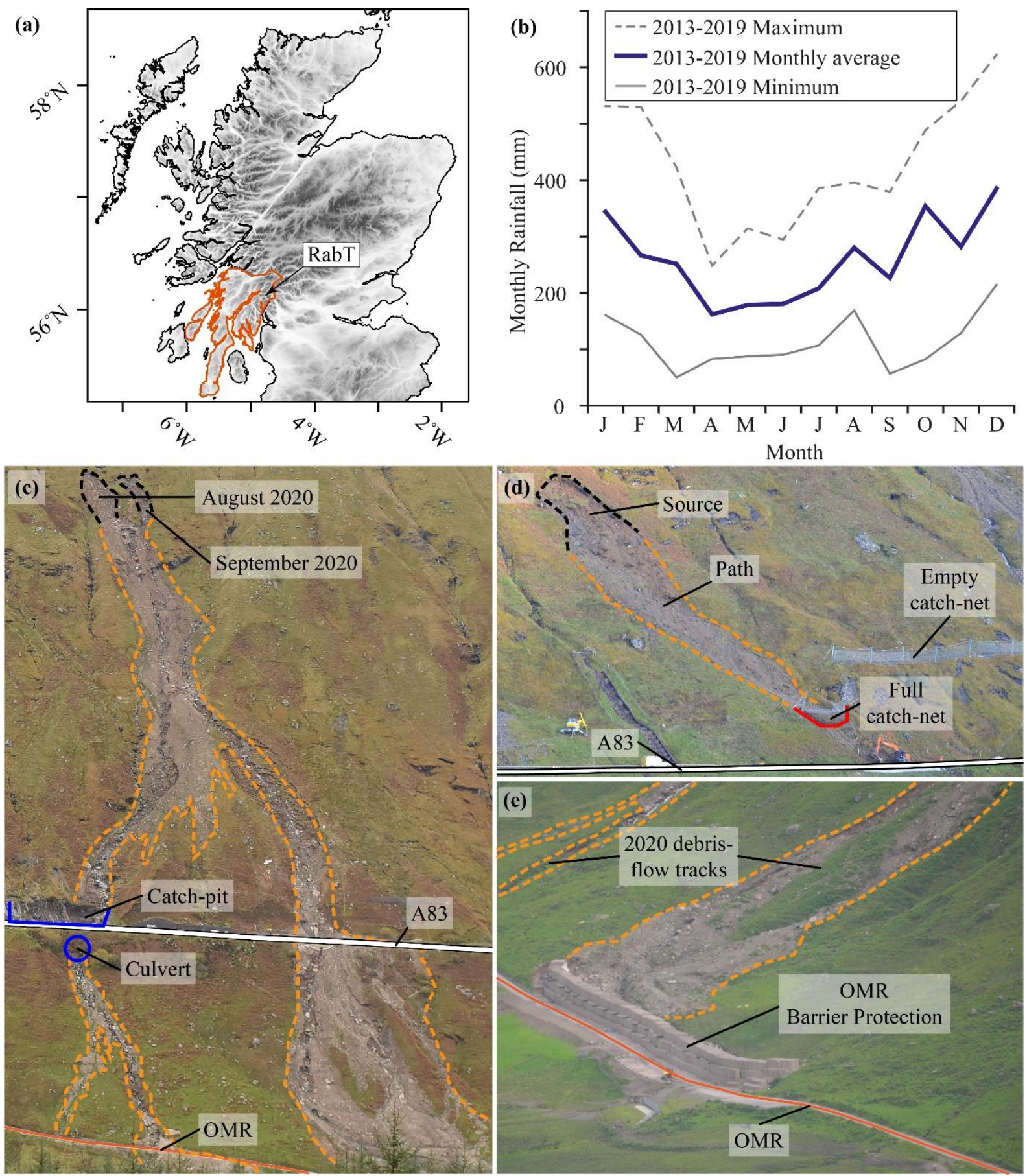

Figure 1. (a) Scotland digital terrain model showing the RabT location and the vulnerability shadow for simultaneous A83/OMR road closures in orange (modified from Winter et al. 2019a). (b) RabT average monthly rainfall from 2013 to 2019 (SEPA RabT gauge; SEPA, 2020). (c) Debris flows from August and September 2020 with catch-pit and culvert mitigation. (d) October $9^{\text {th }} 2018$ debris flow which closed the A83. The catch-net has caught the debris, but some has exceeded the net capacity. (e) View of the OMR debris-flow protection barrier completed in January 2021. 

Agency (SEPA) Rest and Be Thankful rainfall gauge is $3118 \mathrm{~mm}$ per year, with on average most rainfall occurring in October to February (Fig 1b). However, August also appears to be generally as wet as winter months and there is considerable variation in monthly rainfall between different years (Fig. 1b). The RabT is a good proxy for many sediment laden upland

147 / mountainous systems subject to moderate to high rainfall that are susceptible to a range of slope instabilities and threaten infrastructure.

On average 4,000 vehicles cross the RabT per day (Winter et al. 2019a). Closures divert traffic a maximum $\sim 88 \mathrm{~km}$, if the A83 and Old Military Road (OMR; Fig. 1c), a one-way convoy diversion downslope of the A83, are closed, casting a vulnerability shadow over 4,300 km² (Fig. 1a; Winter et al. 2019a). A full road closure costs £90k per day (2012 prices; Winter et al. 2019a) and $£ 13.3 \mathrm{M}$ has been spent on active protection of the A83, using catch-nets, catch-pits and culvert upgrades (Fig. 1c and d). This cost also includes improving the OMR to handle larger vehicles and higher traffic volumes (Scottish Parliament, 2020). However, some debris flows still exceed mitigation measures and impact the A83 and OMR. From the August 2020 to January 2021 the A83 was closed for 120 days, due to a series of large debris flows in August and September 2020 (Fig. 1c). The OMR convoy diversion was in place for much of the closure time, but additional investment was made to build a $175 \mathrm{~m}$ long, $6.6 \mathrm{~m}$ tall barrier, completed in January 2021 which protects part of the OMR from debris-flows (Fig. 1e). The barrier was installed as a response to the August-September 2020 debris-flows and a period of persistent slope creep above the A83 following those events.

The Scottish Road Network Landslide Study examined the full road network landslide 164 risk and mitigation options (Winter et al., 2005). As a result, semi-quantitative and quantitative risk assessments justified additional passive mitigation measures at the RabT (Winter at al., 2009; Winter and Wong, 2020); as part of the LMP daylight patrols are dispatched and warning 
lights activated on the RabT approach if forecast rainfall is $>=25 \mathrm{~mm}$ in a 24 -hour period or $>=4 \mathrm{~mm}$ in a 3-hour period (Winter et al. 2020), indicating a raised risk of debris flows.

\section{Datasets and Methodology}

\subsection{Landslide inventories}

We have collated a new RabT landslide inventory from road reports (2003-2015), quarterly and event responsive terrestrial laser scans (TLS; 2015-2020) and time-lapse imagery (2017-2020). Post-2015 it is unlikely events are missing as TLS (0.1 m resolution) and timelapse imagery data were used (Sparkes et al., 2017; Khan et al., 2021, and this study). Pre-2015, debris flows that reached the A83 are recorded, but smaller landslides and those not reaching the road may not be. The quarterly and event response TLS point cloud data were used to quantify the volume of landslide source areas using the M3C2 plugin (Lague et al., 2013) in Cloud Compare (Version 2.11.3 Anoia; http://www.cloudcompare.org/), which computes distances between referenced point clouds. The resulting change data were filtered to extract point-to-point losses and gains due to movement of material on the RabT slope. Longitudinal profiles of CDF and HDF source areas have been extracted from TLS point cloud derived digital elevation models (DEMs) of the RabT slope in QT Modeler (Version 8070, Applied Imagery).

\subsection{Rainfall thresholds for landslide alerts}

Rainfall on seasonal, daily and 15-minute timescales are used here as indicators of increased landslide hazard at the RabT. The 2013-2019 seasonal rainfall trend was examined for the Scottish Environment Protection Agency (SEPA) RabT rain gauge data (SEPA, 2020) using the Bayesian Estimator of Abrupt change, Seasonality and Trend (BEAST) analysis package (Zhao et al., 2019). BEAST uses ensemble modelling, where multiple competing models analyse data, and Bayesian statistics derive a model average with associated probabilities that detect if seasonal and trend changes are 'true'. BEAST identifies seasonal 
change points (SCPs) when rainfall has large inter-annual variations, i.e. the seasonal component of the rainfall time-series changes between the same time in different years. Trend change points (TCPs) are identified when the rainfall time-series trend changes abruptly. For seasonal and trend components, not all variations will lead to SCPs and TCPs being assigned, only those that have a high probability of being a genuine and significant difference, based on the agreement between competing models.

September to December 2018 was a particularly active landslide period at the RabT and the start of high-temporal and high-spatial resolution datasets at the site, enabling the association of debris flows to rainfall conditions. Therefore, this period is used to look in detail at rainfall conditions at and prior to debris flows.

We calculated the Antecedent Precipitation Index (API; Fedora and Beschta, 1989), a proxy for ground saturation (Segoni et al., 2018), for daily rainfall totals using Equation 1, as an indicator of raised debris flow hazard.

$$
A P I_{i}=k\left(A P I_{i-1}\right)+P_{i}
$$

Where $\mathrm{API}_{i}$ is the API at time $i, \mathrm{P}_{i}$ is the daily rainfall total at $i$ and $k$ is a constant decay function defined by the user $(k=0.8)$. The $k$ value is a conservative estimate based on other works (Heggen, 2001; Viessman and Lewis 1996, Fedora and Beschta, 1989) as no stream gauge data is available for Glen Croe, so storm hydrograph regression analysis to derive a local $k$ estimate was not possible. Rainfall has been measured with an on-slope Davis Vantage Pro 2 gauge (364 m a.s.1) since April 2018, better reflecting on-slope conditions than the off-slope SEPA gauge that $0.85 \mathrm{~km}$ away and $87 \mathrm{~m}$ lower in the valley.

Using 15-minute rainfall intensity data from the on-slope Davis Vantage Pro 2 gauge, we developed an intensity-duration (I-D) threshold over which debris flows have occurred in the past. Duration and mean rain intensity for all storms in the study period were plotted (Brunetti et al. 2010; Guzzetti et al. 2008), with a six-hour inter-event period. An I-D threshold 
above which landslides occur was visually derived from the results (Guzzetti et al. 2008). Mean

217 rain intensity over an entire storm was used, as opposed to mean rain intensity up to the point 218 of the landslide, as not all landslide timings were known due to occlusion of the time lapse 219 camera from the slope from clouds and night-time.

\subsection{Landslide initiation, tracking and detection}

Remote monitoring to detect slope changes can be useful for assessing slope conditions and managing infrastructure, without needing a constant personnel presence on-site. Visual analysis of imagery is useful, however an ability to analyse images pixel-by-pixel, detect changes, and quantify rates of movement provides more data to asset managers. With this ability large areas can be analysed for precursory movement before landslides occur as well as tracking and detecting movement during slope failures. Here, we process time-lapse imagery in a particle image velocimetry tool (PIVLab; Thielicke and Stamhuis, 2014; Thielicke, 2020) to detect creeping deformation on the RabT during mid- to late-September 2018, before a series of roadclosing debris flows in October 2018. This time-period is used here as a good example of what this technology and these data can achieve prior to a series of large slope failures. This PIV tool has since been enhanced by Khan et al. (2021) for automatic image stabilisation, processing, and filtering. Displacement vectors and velocity were established between consecutive slopewide images at $16 \times 16$ pixel resolution $\left(\sim 2.7 \mathrm{~m}^{2}\right)$. Sequential deformation was derived for a point tracked through the photo sequence and inverse velocity (I-V), an analytical approach used to predict failure in brittle materials (Carlà et al., 2017), was used as an indicative metric the RabT appear to move as rafts of intact material over a discrete, progressively forming shear 238 surface, and, as such have more in common with brittle failure than ductile deformation. Imminent failure is predicted when I-V values reach zero (infinite velocity), in theory, and, 
241 al. 2020). Intervals between usable daylight images was not uniform due to cloud, rain, and 242 night-time obscuration, so velocity data from PIVLab were interpolated to $12 \mathrm{~h}$ intervals, with 243 a moving average smoothing of $24 \mathrm{~h}$. I-V was calculated for smoothed data using $1 /(V w)$ (e.g. 244 Manconi and Giordan, 2016), where $V$ is velocity over the defined time window $(w)$.

We used seismic monitoring to detect the precise timing of debris flow onset. Industry standard seismometers are used for the detection of debris flows in catchment scale torrent systems (Walter et al., 2017) and the slope failure source areas that cause them (Burtin et al. 2016). Here we deploy a low-cost Raspberry Shake 3D seismometer (Raspberry Shake, 2020; Manconi et al., 2018) for directional detection of debris flows on a steep hillslope with uncertain flow initiation and routing, and short flow paths. The seismogram trace shows characteristic debris flow signals (Burtin et al. 2016), generated through clast-clast and flow-substrate interactions, above the long-term average. Conventional seismics uses cross-correlation between stations to geolocate the event generating the seismic signal (Burtin et al. 2016). Here we use hodograms (plotting signal direction through time; Borella et al., 2019) to confirm the direction of debris flow signals to the seismometer as we only had a single station deployed on the site.

\section{Results}

Effective road asset management requires information on raised threats of landslide activity, significant slope changes, precursory movement and, finally, post-failure adjustment during remedial works. These data all need the context of long-term activity. This enables stakeholders to be on stand-by, pre-position resources, or proactively manage risk with targeted interventions. Here we show how the methodologies are applied to achieve alerts of high activity periods within long-term records, to quantify threshold preconditions to failure, and to 

three of unknown type); 12 slope creep events, defined as a relatively slow gravitational deformation of material; and 9 debris falls (Hungr et al. 2014), which in the case of the RabT are small $\sim 1 \mathrm{~m}^{3}$ failures of surficial material, often from the top of bedrock outcrops, which do not propagate downslope (Fig. 2). Seventeen debris flows closed the A83, on average once a year since 2003 though this masks the often clustered nature of events in time; eight reached the OMR which requires a full diversion.

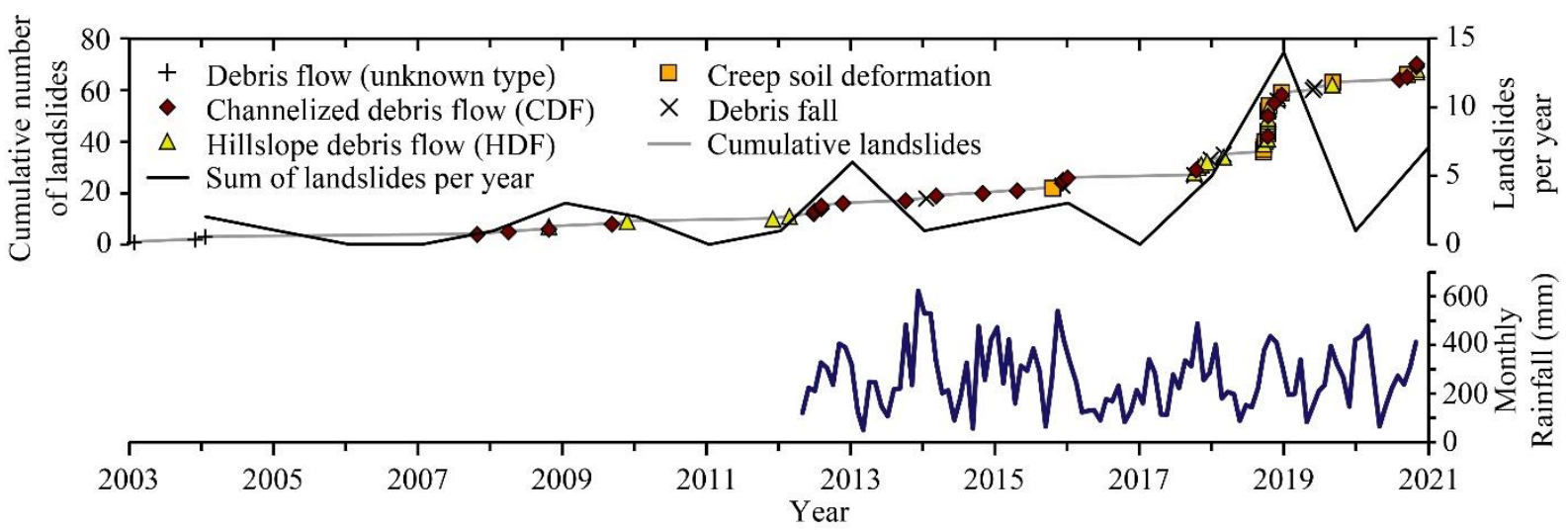

Figure 2. 2003 to 2020 cumulative landslide timeseries and yearly totals. Monthly rainfall is shown from the off-slope SEPA Rest and be Thankful gauge for the period that it is available. (2015-2019) or estimates from reports (2007-2015). Thirty-six are debris flows, seven debris falls and ten creep deformations. Combining the debris flows and debris falls, $18 \%$ of the landslide source volume originates from the debris cones (22\% of the slope by area); whilst till (61\% of the slope by area) and regolith (18\% of the slope by area) account for $67 \%$ and $15 \%$ of the landslide source volume respectively (Table 1). Creep landslide volumes were excluded from the above volumetric analysis, as it is not possible to accurately measure the volume of the entire moving mass from TLS data, given that much of the failed material has not been 
evacuated from the source area. For creep landslides it is only possible to calculate the surface volume loss. Creep landslides were found in the debris cones $(n=7)$ and till $(n=3)$. Most of the

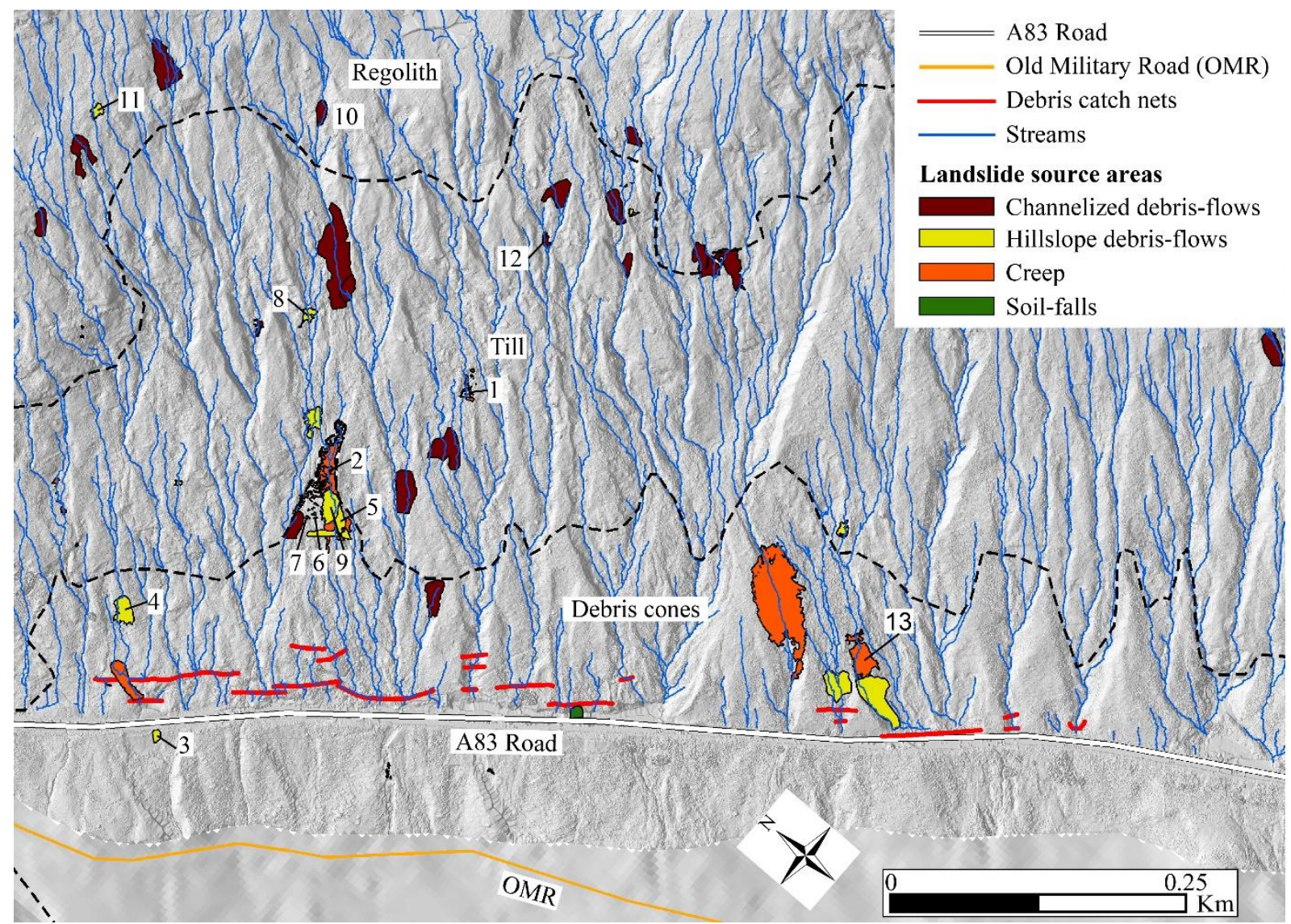

Figure 3. RabT landslide inventory. TLS derived hillshade and 2007 to 2019 landslide source areas, coloured by the resulting failure type. Surface material delineation (dashed lines) modified from Finlayson, 2020. Numbers refer to Fig. 6. are generally long $(15-50 \mathrm{~m})$ and with the deepest recorded failures; there is a more varied original surface-to-failure plane depth profile from debris-cone sources (Fig. 4; Table 2). Tillbased failure planes vary between $5 \mathrm{~m}$ and $35 \mathrm{~m}$ in length with a shallower depth profile (average $1.2 \mathrm{~m}$ ); whilst regolith failures are between $5 \mathrm{~m}$ to $25 \mathrm{~m}$ with a shallow average depth 
profile of $0.77 \mathrm{~m}$ (Fig. 4). The average surface slope of the RabT is $\sim 32^{\circ}$ and average failure

300 plane slopes for all material types range between $30^{\circ}$ and $31^{\circ}$. Extrapolation of gully pathways

301 from a TLS derived DEM, shows a strong coupling of source areas with stream flow paths

302 (streams in Fig. 3).

303 Table 1. Summary of contribution (by area and volume) of different material source areas to 304 the slope failure types occurring at the site.

\begin{tabular}{|l|c|c|c|}
\cline { 2 - 4 } \multicolumn{1}{c|}{} & Debris Cones & Till & Regolith \\
\hline Number of debris flows and debris falls & 11 & 21 & 11 \\
\hline Number of creep landslides & 7 & 3 & 0 \\
\hline$\%$ areal slope coverage & 22 & 61 & 18 \\
\hline$\%$ source area volume contribution & 18 & 67 & 15 \\
\hline
\end{tabular}

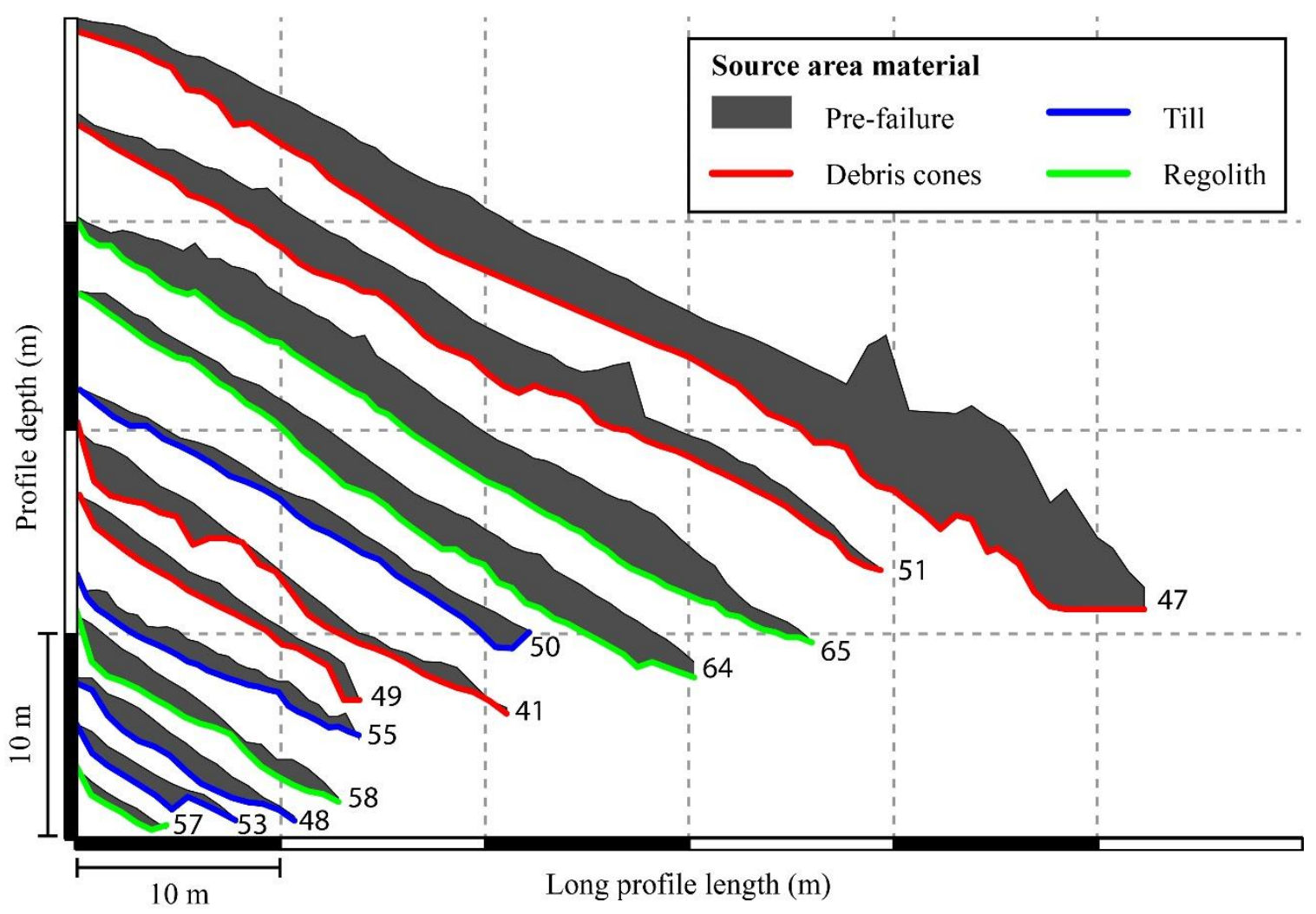

Figure 4. Example debris flow source area long profiles (2018-2020), derived from TLS point clouds, showing pre- and post-failure surface elevations. Profiles are coloured by source material type. Profiles are numberd by the landslide inventory. 
Table 2. Descriptive statistics for the depth profiles in Figure 4.

\begin{tabular}{|l|c|c|c|c|c|c|}
\cline { 2 - 7 } & \multicolumn{6}{c|}{ Inventory landslide number } \\
\cline { 2 - 7 } & $\mathbf{4 1}$ & $\mathbf{4 7}$ & $\mathbf{4 8}$ & $\mathbf{4 9}$ & $\mathbf{5 0}$ & $\mathbf{5 1}$ \\
\hline Material & Debris & Debris & Till & Debris & Regolith & Debris \\
\hline Minimum depth & 0.03 & 0.63 & 0.21 & 0.47 & 0.13 & 0.34 \\
\hline Maximum depth & 2.3 & 7.6 & 1.61 & 1.79 & 1.75 & 3.27 \\
\hline Average depth & 0.79 & 3.33 & 0.94 & 0.85 & 0.83 & 1.54 \\
\hline $\begin{array}{l}\text { Standard deviation } \\
\text { of profile depth }\end{array}$ & 0.62 & 1.82 & 0.43 & 0.32 & 0.34 & 0.7 \\
\hline
\end{tabular}

Table 2 (Cont.). Descriptive statistics for the depth profiles in Figure 4.

\begin{tabular}{|l|c|c|c|c|c|c|}
\cline { 2 - 7 } & \multicolumn{6}{c|}{ Inventory landslide number } \\
\cline { 2 - 8 } & $\mathbf{5 3}$ & $\mathbf{5 5}$ & $\mathbf{5 7}$ & $\mathbf{5 8}$ & $\mathbf{6 4}$ & $\mathbf{6 5}$ \\
\hline Material & Regolith & Regolith & Till & Till & Till & Till \\
\hline Minimum depth & 0.08 & 0.32 & 0.53 & 0.2 & 0.27 & 0.04 \\
\hline Maximum depth & 1.27 & 1.22 & 0.72 & 1.93 & 2.6 & 3.2 \\
\hline Average depth & 0.64 & 0.81 & 0.4 & 1.02 & 1.54 & 2.15 \\
\hline $\begin{array}{l}\text { Standard deviation } \\
\text { of profile depth }\end{array}$ & 0.04 & 0.24 & 0.74 & 0.49 & 0.61 & 0.79 \\
\hline
\end{tabular}

Rainfall on seasonal, daily, and 15-minute timescales has been used to indicate raised

316 landslide hazard. BEAST identified six rainfall seasonal change points (SCP) in winter periods 317 from 2013 to 2020 (Fig. 5a). SCP4 coincides with Storms Desmond and Frank which caused 318 debris flows at the RabT. SCP6 in mid-2020 shortly precedes the large August-September 319 debris flows that shut the A83. No SCPs are seen from 2016 to late-2019, but landslides do 320 still occur. Instead, many debris flows are coincident with abrupt rainfall trend change points 
321 (TCPs) as well as their subsequent falling trends, and long period high trends (Fig. 5b). TCPs
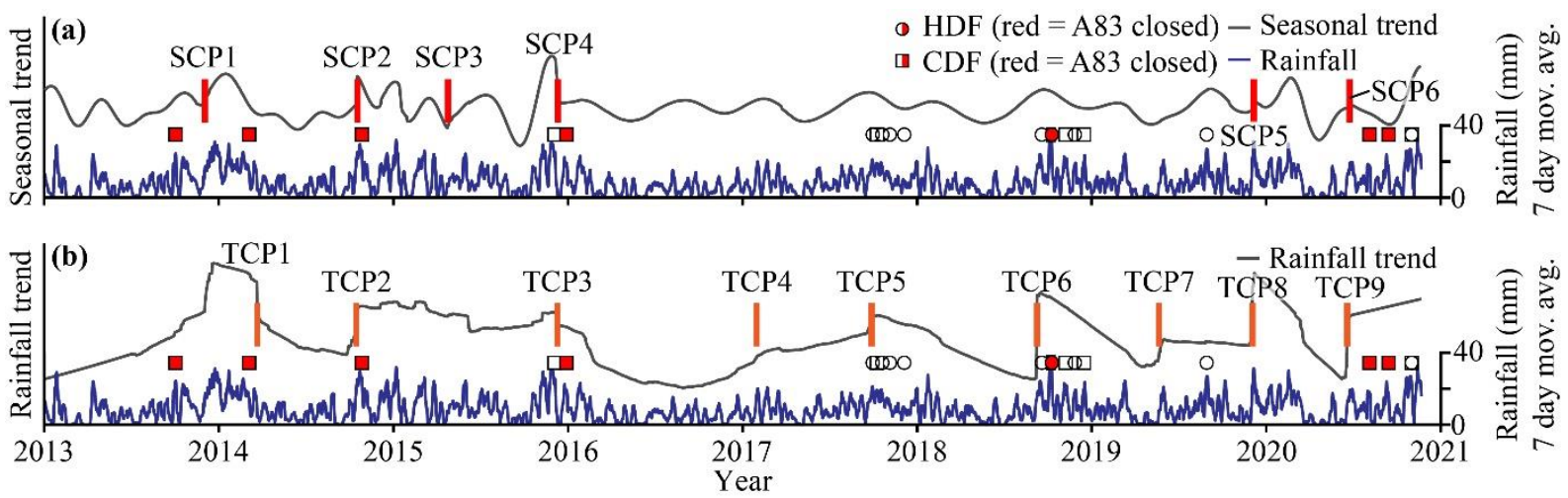

Figure 5. (a) BEAST seasonal rainfall component. (b) BEAST rainfall trend.

TCP6 starts the 2018 landslide period, a particularly active year with 19 of the 63

landslides (Fig. 2). Here we use September to December 2018, a particularly active time-period

at the RabT, as a case study to highlight the effectiveness of pro-active, near-real-time

monitoring to alert asset managers to increased landslide hazard based on rainfall thresholds,

tracking slope creep, and detecting debris flow occurrence. Time-lapse imagery has allowed the timings of the 2018 landslides to be more accurately detected, allowing the identification of specific rainstorms where landslides have occurred.

For the late-2018 period Fig. 6 shows when LMP forecast rainfall thresholds were exceeded and warning lights were operating, along with the same thresholds plotted using onslope, live rain data. These data are summarized in confusion matrices which describe the performance of the rainfall thresholds in detecting conditions that triggered landslides; data are described as times where thresholds predict landslides will or will not happen against times where landslides did or did not occur. False alarms and missed landslides account for $6.9 \%$ of the study period for warning lights and $12.2 \%$ for on-slope data (Table 3). 


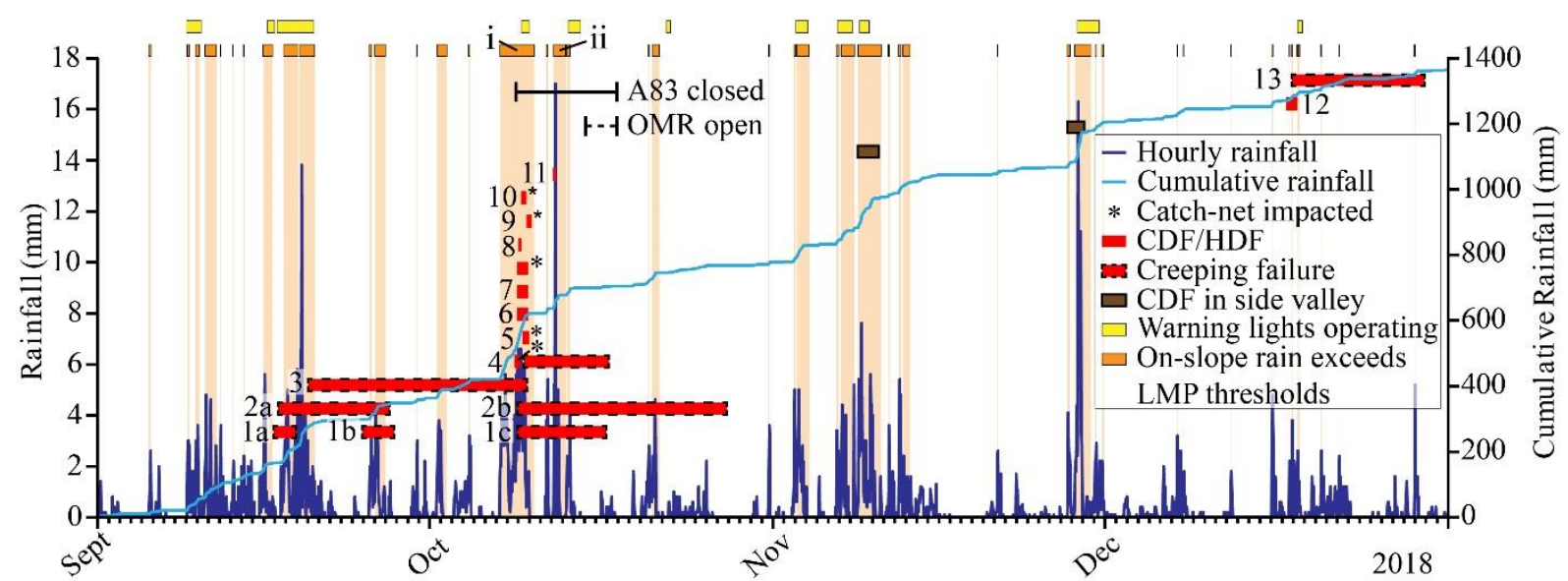

Figure 6. 01 September to 31 December 2018 landslides, warning light activations from the current LMP thresholds (where forecast data is used) and activations that would have occurred using real-time on-slope data. On-slope rainfall data is from the Newcastle University Davis gauge.

Table 3. Warning light and on-slope alert operation confusion matrix.

\begin{tabular}{|l|lll|l|}
\cline { 2 - 5 } \multicolumn{1}{l|}{ \% of study period } & \multicolumn{2}{|c|}{ Landslide } & \multicolumn{2}{l|}{ No Landslide } \\
\hline Warning lights ON / On-Slope ON & $\mathbf{6 . 6 \%}$ & $7.7 \%$ & $\mathbf{4 . 1 \%}$ & $11.1 \%$ \\
\hline Warning lights OFF / On-Slope OFF & $\mathbf{2 . 8 \%}$ & $1.1 \%$ & $\mathbf{8 6 . 5 \%}$ & $80.1 \%$ \\
\hline
\end{tabular}

Warning lights are human operated, reducing false alarms through expert judgement.

However, on-slope data would raise alert levels two times where landslides occurred, that are not fully covered by the warning lights (Fig. $6 \mathrm{i}$ and ii). To improve on the current LMP rainfall thresholds for predicting hazardous debris flow conditions on the RabT, shown in Figure 6 and Table 3, we now look at the intensity and duration of rainstorms which generated landslides, and antecedent precipitation.

Landslide producing storms in 2018 were medium $(>10 \mathrm{~h})$ to long duration (max. 72h;

Fig. 7); however, for two storms it was not possible to determine in which the landslide happened. Mean rain intensity for landslide initiation ranges from $2.95 \mathrm{~mm} / \mathrm{hr}$ to $8.15 \mathrm{~mm} / \mathrm{hr}$. Landslides occur above the threshold described by Equation 2.

$$
I=4.75 D^{-0.18}
$$


Where $I$ is mean rain intensity and $D$ is duration. As all confirmed landslide storms were $>10 \mathrm{~h}$ duration, the threshold may not apply to $<10 \mathrm{~h}$ storms. The I-D threshold gives a false alarm for $5.7 \%$ of the study period (Table 4 ).

All landslides $(\mathrm{n}=18)$ occur over an API threshold of $37 \mathrm{~mm}$, with three false alarms and long periods of alert with no landslides (Fig. 8). A $62 \mathrm{~mm}$ API threshold covers $90 \%$ of landslides ( $\mathrm{n}=16)$, reduces false alarms to $0.8 \%$ of the study period (Table 4$)$, but misses two mid-December events. A combination of I-D and API thresholds maximizes landslide detection and minimizes false alarms (Table 4). All landslide inducing storms exceed the I-D threshold with five false alarms (Fig. 8 i to v) which API thresholds reduce to two (Fig. 8 iv, v).

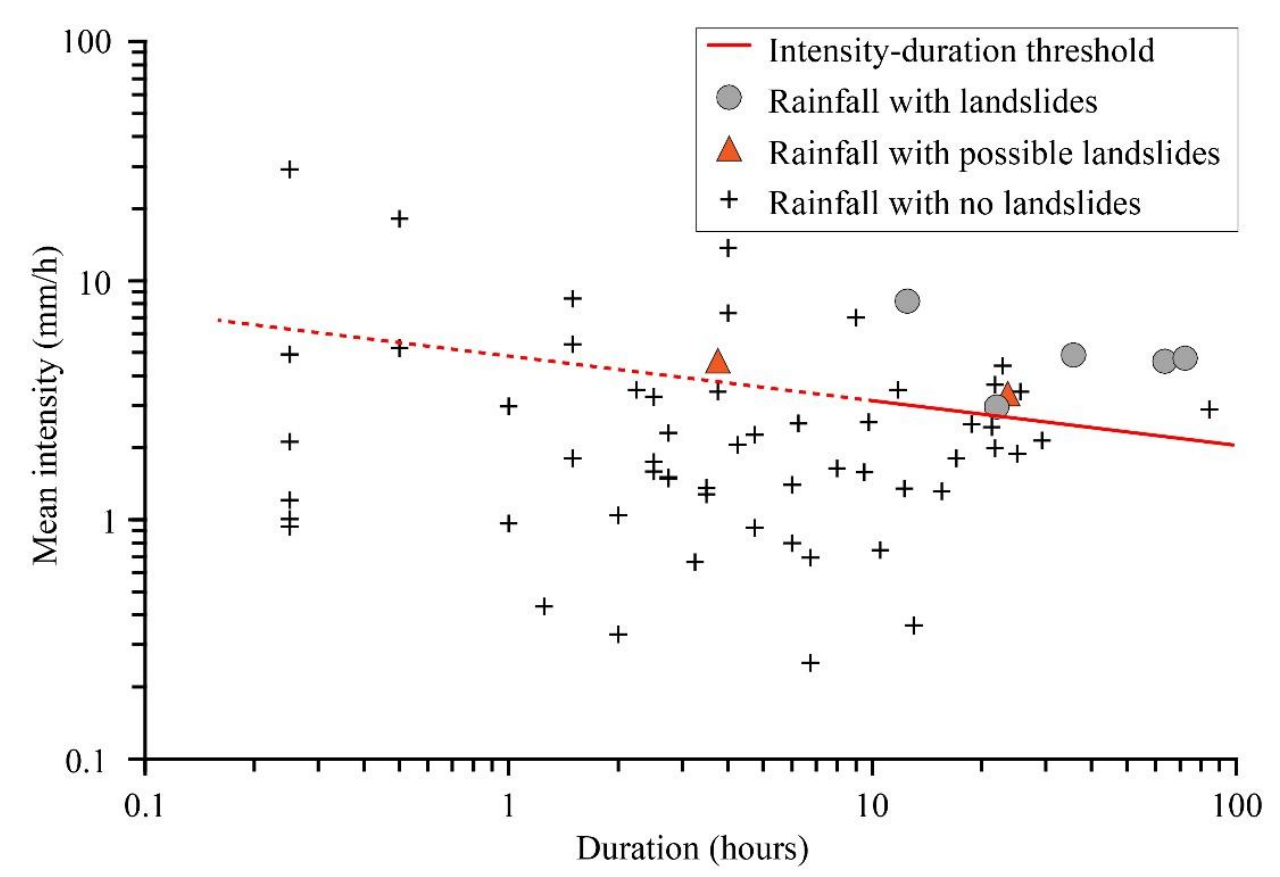

Figure 7. September to December rainstorm intensity-duration (I-D) plot.

Table 4. API and I-D threshold confusion matrix. Current LMP statistics are summarised in Table 3.

\begin{tabular}{|c|c|c|}
\hline$\%$ of study period & Landslide & No Landslide \\
\hline API $>$ threshold $/$ I-D $>$ threshold & $\mathbf{2 9 . 5 \%} 8.2 \%$ & $\mathbf{0 . 8 \%} \quad 5.7 \%$ \\
\hline API $<$ threshold $/$ I-D $<$ threshold & $3.3 \% \quad 0.0 \%$ & $\mathbf{8 1 . 0 \%} 86.1 \%$ \\
\hline
\end{tabular}




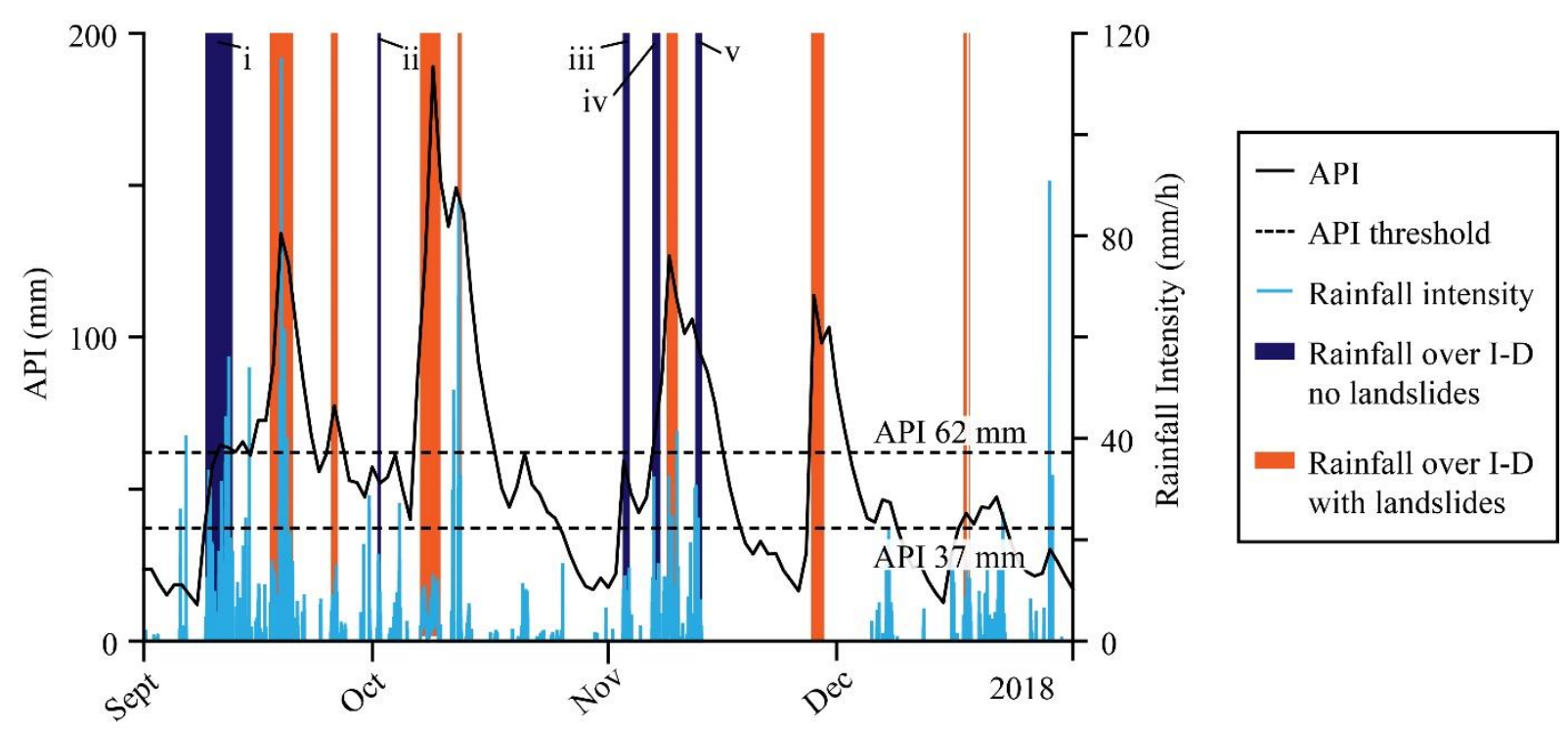

371

Figure 8. Antecedent Precipitation Index (API) with $37 \mathrm{~mm}$ and $62 \mathrm{~mm}$ thresholds. Rainfall intensity (data loss 13 November to 05 December) with storms $>10$ h duration exceeding the ID threshold.

\subsection{Early warning of slow creeping failures}

We monitored the creep of Failure 2 (Fig. 6) via time-lapse image vector tracking from initiation (19 September 2018) to arrest (27 September 2018) using PIVLab (Thielicke and Stamhuis, 2014; Thielicke, 2020; Khan et al., 2021). Vectors of change and a velocity heat map between consecutive images are shown in Figs. 9a and 9b.

Creep initiation coincides with a rainstorm on the 18 September 2018 (Fig. 9c i). Half of the total cumulative deformation occurs in the first 2.5 days. Inverse velocity (I-V) rapidly decreases towards zero on the 19-20 September 2018; extrapolation of the I-V trend predicts failure on the 21 September 2018. However, I-V values increase on the 21 September, indicating reduced velocity after rainfall ceases. The deformation rate slows until arrest (Fig. 9c ii) and subsequent rainfall does not affect the deformation rate and (Fig. 9c iii). Operationally, alert levels would be raised in Phase i when imminent failure seemed likely but lowered in Phase ii. 

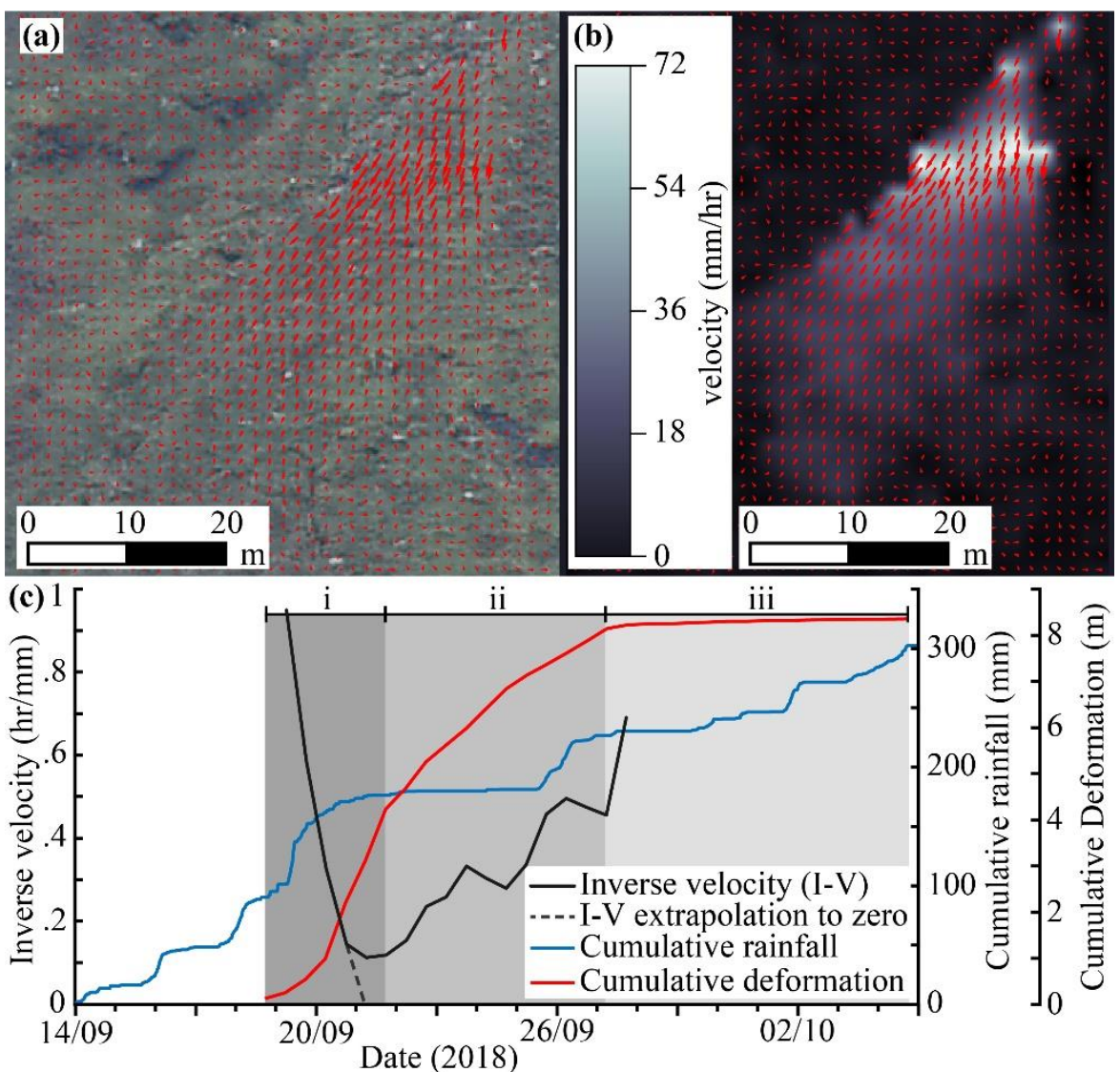

389 Figure 9. (a) PIVLab deformation vector plot (Thielicke and Stamhuis, 2014). (b) Velocity heat 390 map. (c) Cumulative rainfall, cumulative deformation, and I-V.

\subsection{Detecting rapid debris flows}

Seismic monitoring identified a HDF (Figs. 10a and 10b) on the 09 October 2018 and

located the source area. The z-axis seismogram (Fig. 10c) shows a high-amplitude signal lasting

$\sim 15 \mathrm{~s}$, corresponding with the failure time derived from time-lapse imagery, which is likely the

HDF in motion. Short duration, lower amplitude signals follow and are likely post-landslide

sediment and boulder reworking. Hodograms show very little activity at first (Fig. 10c i), but

signal strength increases as the HDF signal arrives (ii) before subsiding (iii). Stacked 

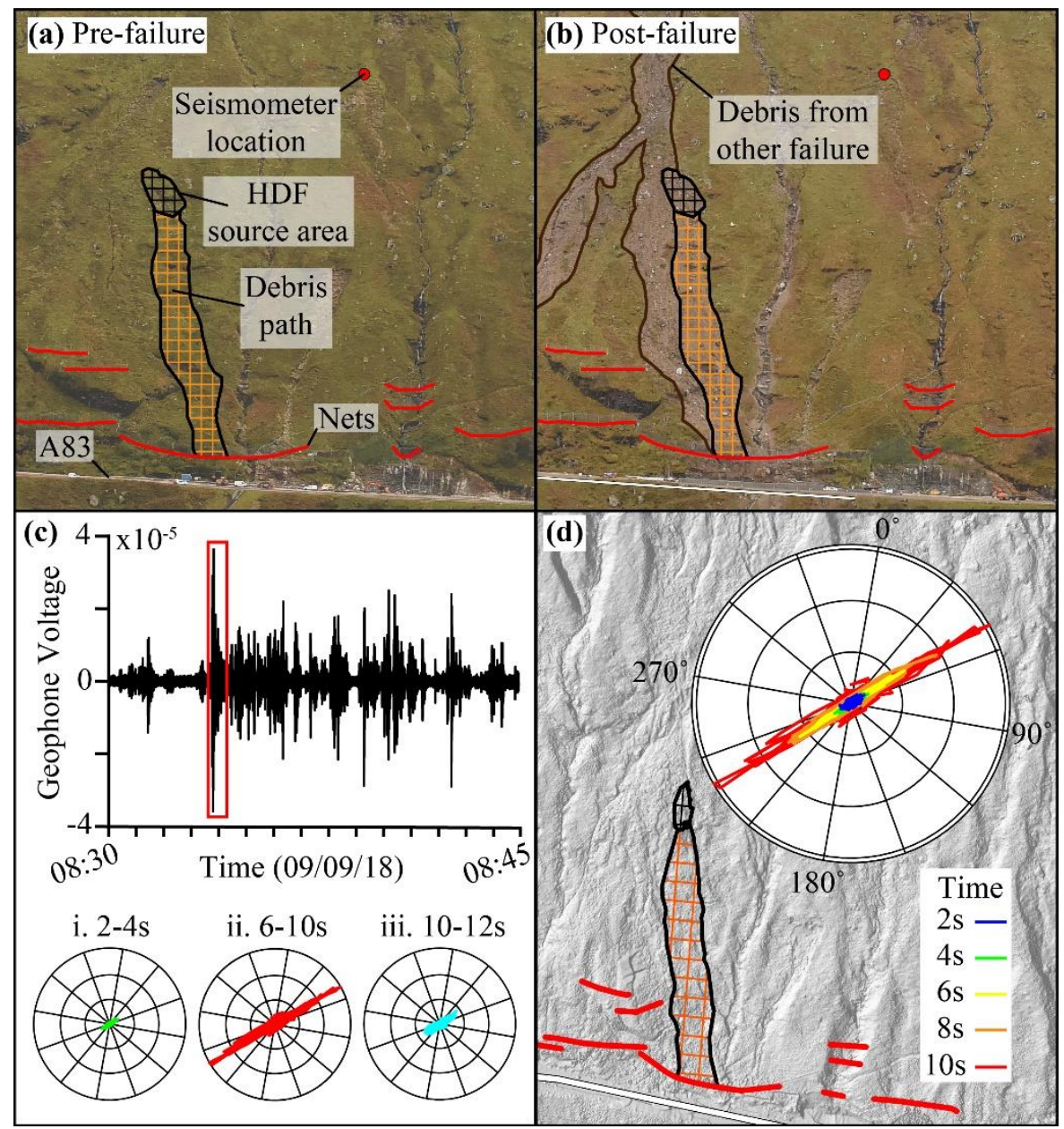

401 Figure 10. (a) Pre-failure HDF source and seismometer location. (b) Post-failure. (c) Fifteen402 minute seismogram with HDF signal (red box) and three hodogram time-steps (i, ii, iii). (d) 403 Hillshade with HDF location and ten second stacked hodogram. and sediment reworking post-event. Another deposit on Fig. 10b, which is a thin, fine-grained drape but has a large deposit footprint, was not detected by seismic monitoring; indicating that whilst high debris content flows can be detected, hyper-concentrated flows may need larger station arrays for detection.

\section{Discussion and conclusions}

This paper presents the results of on-site monitoring at the RabT, aimed at 411 supplementing the existing regional LMP (Winter et al., 2009). Together we show that it is 412 possible to devise and refine thresholds for periods of likely increased landslide hazard using 
on-slope rainfall gauges and landslide inventories with accurate timings. Further, we have

414 shown that deformation can be detected and then tracked in near-real time, and, that final rapid

415 failures (which many or may not have shown precusor) can be detected.

Landslides come from three material types on the slope: regolith, till and, debris cones, which

418 exert a control on source area morphology and landslide volumes. Debris cone sources are generally deeper, which likely represents thicker deposits of source material to bedrock. The failure depths sourced in the upslope surface material comprising of glacial till and regolith were significantly shallower. The total volume of source areas for debris flows and debris falls across the slope is $5,404 \mathrm{~m}^{3}$, with debris cones accounting for $18 \%\left(984 \mathrm{~m}^{3}\right)$, regolith $15 \%(823$ $\left.\mathrm{m}^{3}\right)$ and till the remaining $67 \%\left(3,597 \mathrm{~m}^{3}\right)$. Each material type accounts for a proportion of source volumes similar to their areal coverage of the slope, indicating that no one material produces relatively more landslide volume than any other. However, debris cones produce fewer but larger landslides, whilst till and regolith sources produce smaller but more frequent landslides. Debris-flows in till have closed the road seven times compared to four and three times for regolith and debris cones respectively. Debris flows in till could therefore be considered as the greatest risk to road closure. Similar failure plane slope angles of $30^{\circ}$ to $31^{\circ}$ indicate a control on landslide initiation, which may represent a critical threshold within the slope material or relate to the dip angle of the underlying bedrock - although most failure are not at the bedrock-cover interface.

BEAST rainfall analysis shows that debris flows are primarily associated with abrupt rainfall trend changes, but that in some cases there is a larger seasonal signal associated with debris flow occurrence. In the 2018 study period, antecedent, and medium- to long-duration, 
alarms, improve on the LMP and provide road authorities time to consider actions. $90 \%$ of

439 RabT landslides occurred over a $62 \mathrm{~mm}$ API, indicating a critical antecedent rainfall threshold.

440 Rainstorm I-D $>10 \mathrm{~h}$ is key for landslide initiation with largely higher mean rain intensity than 441 non-landslide storms. Whilst the thresholds have been calculated locally at the RabT, the 442 surface geology and the topography of the site are replicated in and representative of the 443 surrounding mountain range, indicating that the thresholds potentially apply more regionally 444 although there is not currently a wider, timed inventory of failures.

Time-lapse vector tracking located and quantified creeping deformation in response to rainfall drivers. I-V calculations forecast imminent failure in the initiation phase, however creep slowed when rainfall ceased and arrested despite further rainfall. This method can detect slope movement and indicate times of heightened risk of failure for management authorities. instance, and likely others due to short RabT flow paths, the 15 second event duration is too brief for live warnings but allows for 24/7 event detection and rapid response, outside of timelapse image capture. Additional seismometers (now deployed) extend the range of detection and allow more traditional geo-location. monitoring and quantification of shallow landslides as demonstrated at the RabT in the west of Scotland. Results show that local sensor systems improve our understanding of triggers by allowing landslides to be attributed to specific time periods and therefore the conditions leading to their initiation are better quantified. This allows the forecasting of conditions that will likely 459 induce landslides at the RabT, however the techniques could be readily applied to other sites. Low-cost sensors can be replicated at high- and lower-risk sites where cost-benefit would normally prevent monitoring. Increased high-intensity rainfall due to climate warming is expected in Scotland (UKCP, 2018), meaning more infrastructure and assets will have 
increased debris flow risk. These combined low-cost monitoring techniques are an essential

464 advancement and now operationally proven approach for addressing this future risk.

465

466

467

468

469

470

471

472

473

474

475

476

477

478

479

480

481

482

483

484

485

486

487

488

489

\section{Acknowledgements}

We thank NERC (NE/P000010/1, NE/T00567X/1, NE/T005653/1), Research England (www.Pitch-in.ac.uk 'SlopeRIoT'), Transport Scotland and the Scottish Road Research Board (SRRB) for funding. We also thank BEAR Scotland, GeoRope, Jacobs, Forestry and Land Scotland, Glencroe Farm and John Mather for research, access, and on-site support. Datasets for this research are available from the Newcastle University Data Repository (https://figshare.com/s/058074e7a14320a994ce). We declare no conflicts of interest.

\section{References}

Badoux, A., Graf, C., Rhyner, J., Kuntner, R. and McArdell, B.W. (2009). A debris-flow alarm system for the Alpine Illgraben catchment: design and performance. Natural Hazards, 49, 517-539, https://doi.org/10.1007/s11069-008-9303-x

Bennett, G.L., Molnar, P., McArdell, B.W. and Burlando, P. (2014). A probabilistic sediment cascade model of sediment transfer in the Illgraben. Water Resources Research, 50, 12251244, https://doi.org/10.1002/2013WR013806

BGS (2020). Onshore GeoIndex, https://mapapps2.bgs.ac.uk/geoindex/home.html (accessed June 2020)

Borella, J., Quigley, M., Krauss, Z., Lincoln, K., Attanayake, J., Stamp, L. et al. (2019). Geologic and geomorphic controls on rockfall hazard: how well do past rockfalls predict future distributions? Natural Hazards and Earth System Sciences, 19, 2249-2280, https://doi.org/10.5194/nhess-19-2249-2019

Brunetti M.T., Peruccacci, S., Rossi, M., Luciani, S., Valigi, D. and Guzzetti, F. (2010). Rainfall thresholds for the possible occurrence of landslides in Italy. Natural Hazards and Earth Systems Science, 10, 447-458. https://doi.org/10.5194/nhess-10-447-2010

Burtin, A., Hovius, N., McArdell, B. W., Turowski, J. M., and Vergne, J. (2016). Seismic constraints on dynamic links between geomorphic processes and routing of sediment in a 
490

491

492

493

494

495

496

497

498

499

500

501

502

503

504

505

506

507

508

509

510

511

512

513

514

515

516

517

518 520

519 Huebl, J. and Fiebiger, G. (2005). Debris-flow mitigation measures, in Jakob, M. and Hungr,

steep mountain catchment, Earth Surface Dynamics, 2, 21-33, https://doi.org/10.5194/esurf2-21-2014

Carlà, T., Intrieri, E., Di Traglia, F., Nolesini, T., Gigli, G and Casagli, N. (2017). Guidelines on the use of inverse velocity method as a tool for setting alarm thresholds and forecasting landslides and structure collapses. Landslides, 14, 517-534. https://doi.org/10.1007/s10346016-0731-5

Chen, J-C., Lin, C-W., and Wang, L-C. (2009). Geomorphic Characteristics of Hillslope and Channelized Debris Flows: A Case Study in the Shitou Area of Central Taiwan. Journal of Mountain Science, 6, 266-273. https://doi.org/10.1007/s11629-009-0250-0

Curry, A.M. (2000). Holocene reworking of drift-mantled hillslopes in the Scottish Highlands. Journal of Quaternary Science, 15, 529-541.

https://doi.org/10.1191/095968300666146993

Fan, X., Xu, Q., Liu, J., Siva Subramanian, S., He, C., Zhu, X. and Zhou, L. (2019).

Successful early warning and emergency response of a disastrous rockslide in Guizhou province, China. Landslides, 16, 2445-2457. https://doi.org/10.1007/s10346-019-01269-6

Fedora, M.A. and Beschta, R.L. (1989). Storm runoff simulation using an Antecedent Precipitation Index (API) model. Journal of Hydrology, 112, 121-133.

https://doi.org/10.1016/0022-1694(89)90184-4

Finlayson, A. (2020). Glacial conditioning and paraglacial sediment reworking in Glen Croe (the Rest and be Thankful), western Scotland. Proceedings of the Geologists' Association, 131(2), 138-154. https://doi.org/10.1016/j.pgeola.2020.02.007

Gertseema, M., Schwab, J.W., Blais-Stevens, A. and Sakals, M.E. (2009). Landslides impacting linear infrastructure in west central British Columbia. Natural Hazards, 48, 59-72. https://doi.org/10.1007/s11069-008-9248-0

14 Guzzetti, F., Peruccacci, S., Rossi, M. and Stark, C.P. (2008). The rainfall intensity-duration control of shallow landslides and debris flows: an update. Landslides, 5, 3-17.

https://doi.org/10.1007/s10346-007-0112-1

Heggen, R.J. (2001) Normalized antecedent precipitation index, Journal of Hydrologic Engineering, 6, 377-381. https://doi.org/10.1061/(ASCE)1084-0699(2001)6:5(377) O., eds., Debris-flow Hazards and Related Phenomena, 445-487. Springer, Berlin Heidelberg 
521 Hungr, O., Leroueil, S. and Picarelli, L. (2014). The Varnes classification of landslide types, 522 an update. Landslides, 11, 167-194. https://doi.org/10.1007/s10346-013-0436-y

523 Innes, J.L. (1983). Lichenometric dating of debris-flow deposits in the Scottish Highlands. Earth Surface Processes and Landforms, 8, 579-588. https://doi.org/10.1002/esp.3290080609 Jones, M.R., Fowler, H.J., Kilsby, C.G. and Blenkinsop, S. (2013). An assessment of changes 526 in seasonal and annual extreme rainfall in the UK between 1961 and 2009: International Journal of Climatology, 33, p. 1178-1194, https://doi.org/10.1002/joc.3503

528 Khan, M.W., Dunning, S., Bainbridge, R., Martin, J., et al. (2021). Low-Cost Automatic 529 Slope Monitoring Using Vector Tracking Analyses on Live-Streamed Time-Lapse Imagery, 530 Remote Sensing, 13(5), 893, https://doi.org/10.3390/rs13050893

531 Lague, D., Brodu, N. and Leroux, J. (2013). Accurate 3D comparison of complex topography 532 with terrestrial laser scanner: Application to the Rangitikei canyon (N-Z), ISPRS Journal of Photogrammetry and Remote Sensing, 82, 10-26, https://doi.org/10.1016/j.isprsjprs.2013.04.009

535 Luckman, B.H. (1992). Debris Flows and Snow Avalanche Landforms in the Lairig Ghru, 536 Cairngorm Mountains, Scotland. Geografiska Annaler: Series A, Physical Geography, 74:2537 3, 109-121, https://doi.org/10.1080/04353676.1992.11880355

538 Manconi, A., Coviello, V., Galletti, M. and Seifert, R. (2018). Short Communication: 539 Monitoring rockfalls with the Raspberry Shake. Earth Surface Dynamics, 6, 1219-1227. 540 https://doi.org/10.5194/esurf-6-1219-2018

541 Manconi, A. and Giordan, D. (2016). Landslide failure forecast in near-real-time. Geomatics, 542 Natural Hazards and Risk, 7:2, 639-648. https://doi.org/10.1080/19475705.2014.942388

543 Meyer, N., Schwanghart, W., Korup, O. and Nadim, F. (2015). Roads at risk: traffic detours 544 from debris flows in southern Norway. Natural Hazards and Earth System Science, 15, 985545 995. https://doi.org/10.5194/nhess-15-985-2015

546 McMillan, F.N. and Holt, C.A. (2018). BEAR Scotland NW trunk road maintenance: efficient 547 management of geotechnical emergencies. Quarterly Journal of Engineering Geology and 548 Hydrogeology, 52, 286-294. https://doi.org/10.1144/qjegh2018-035

549 Milne, F.D., Werritty, A., Davies, M.C.R. and Brown, M.J. (2009). A recent debris flow event 550 and implications for hazard Management. Quarterly Journal of Engineering Geology and 551 Hydrogeology, 42, 51-60. https://doi.org/10.1144/1470-9236/07-073 
552 Ozturk, U., Saito, H., Matsushi, Y., Crisologo, I. and Schwanghart, W. (2021) Can global

553 rainfall estimates (satellite and reanalysis) aid landslide hindcasting?. Landslides,

554 https://doi.org/10.1007/s10346-021-01689-3

555 Raspberry Shake (2020). https://raspberryshake.org/ (accessed June 2020)

556 Scottish Parliament (2020). Official Report of the Public Petitions Committee, 05 March

557 2020. http://www.parliament.scot/parliamentarybusiness/report.aspx?r=12561 (accessed, July 558 2020)

559 Segoni, S., Rosi, A., Lagomarsino, D., Fanti, R. and Casagli, N. (2018). Brief communication:

560 Using averaged soil moisture estimates to improve the performances of a regional-scale

561 landslide early warning system. Natural Hazards and Earth System Science, 18, 807-812.

562 https://doi.org/10.5194/nhess-18-807-2018

563 SEPA, (2020). Rest and Be Thankful 15-minute rainfall record.

564 https://www2.sepa.org.uk/rainfall/ (accessed May 2020)

565 Sparkes, B., Dunning, S., Lim, M. and Winter, M.G. (2017). Characterisation of Recent

566 Debris Flow Activity at the Rest and Be Thankful, Scotland, in Mikoš, M., Vilímek, V., Yin,

567 Y. and Sassa, K., eds., Advancing Culture of Living with Landslides, Volume 5 Landslides in

568 Different Environments: WLF: Workshop on World Landslide Forum Conference

569 Proceedings, 51-58. https://doi.org/10.1007/978-3-319-53483-1_8

570 Stanley, T.A., Kirschbaum, D.B., Benz, G., Emberson, R.A., Amatya, P.M., Medwedeff, W.

571 and Clark, M.K. (2021). Data-Driven Landslide Nowcasting at the Global Scale. Frontiers in

572 Earth Science, 9:640043, https://doi.org/10.3389/feart.2021.640043

573 Thielicke, W. (2020). PIVlab - particle image velocimetry (PIV) tool.

574 https://www.mathworks.com/matlabcentral/fileexchange/27659-pivlab-particle-image-

575 velocimetry-piv-tool, MATLAB Central File Exchange. (Accessed July 2020)

576 Thielicke, W. and Stamhuis, E.J. (2014). PIVlab - Towards User-friendly, Affordable and

577 Accurate Digital Particle Image Velocimetry in MATLAB. Journal of Open Research

578 Software, 2 (1), e30. http://doi.org/10.5334/jors.bl

579 UKCP. (2018). UK Climate Projections. Met Office.

580 https://www.metoffice.gov.uk/research/approach/collaboration/ukcp/ (accessed June 2020) 
581 Vagnon, F. (2020). Design of active debris flow mitigation measures: a comprehensive 582 analysis of existing impact models. Landslides, 17, 313-333. http://doi.org/10.1007/s10346$583 \quad 019-01278-5$

584 Viessman, W., Jr., and Lewis, G. L. (1996). Introduction to hydrology. 4th Ed., 585 HarperCollins, New York.

586 Walter, F., Burtin, A., McArdell, B., Hovius, N., Weder, B., Turowski, J.M. (2017). Testing 587 seismic amplitude source location for fast debris-flow detection at Illgraben, Switzerland. 588 Natural Hazards and Earth System Science, 17, 939-955. https://doi.org/10.5194/nhess-17$589 \quad 939-2017$

590 Winter M.G., Macgregor F., Shackman, L. (2009). Scottish Road Network Landslides Study: 591 Implementation, The Scottish Executive, Edinburgh

592 Winter, M.G., Peeling, D., Palmer, D. and Peeling, J. (2019a). Economic impacts of 593 landslides and floods on a road network. AUC Geographica, 54 (2), 207-220, 594 https://doi.org/10.14712/23361980.2019.18

595 Winter, M.G., Ognissanto, F. and Martin, L.A. (2019b). Rainfall Thresholds for Landslides 596 Deterministic and Probabilistic Approaches. Transport Research Laboratory Published 597 Project Report PPR901, https://trl.co.uk/reports/rainfall-thresholds-landslides

598 Winter, M.G., Kinnear, N. and Helman, S. (2020). A technical and perceptual evaluation of a 599 novel landslide early warning system. Proceedings, Institution of Civil Engineers (Transport), 600 https://doi.org/10.1680/jtran.19.00138

601 Winter, M.G. and Wong, J.C.F. (2020). The assessment of quantitative risk to road users from 602 debris flow. Geoenvironmental Disasters, 7(4), 1-19. https://doi.org/10.1186/s40677-019$603 \quad 0140-\mathrm{x}$

604 Xu, Q., Peng, D., Zhang, S., Zhu, X., He, C., Qi, X., Zhao, K., Xiu, D. and Ju, N. (2020) 605 Successful implementations of a real-time and intelligent early warning system for loess 606 landslides on the Heifangtai terrace, China. Engineering Geology, 278.

607 https://doi.org/10.1016/j.enggeo.2020.105817

608 Zhao, K., Wulder, M.A., Hu, T., Bright, R., Wu, Q., Qin, H., et al., (2019). Detecting change609 point, trend, and seasonality in satellite time series data to track abrupt changes and nonlinear 610 dynamics: A Bayesian ensemble algorithm. Remote Sensing of Environment, 232.

611 https://doi.org/10.1016/j.rse.2019.04.034 
612 Zimmerman, F., McArdell, B.W., Rickli, C. and Scheidl, C. (2020). 2D Runout Modelling of 613 Hillslope Debris Flows, Based on Well-Documented Events in Switzerland. Geosciences, 614 10(2):70. https://doi.org/10.3390/geosciences10020070 